\title{
Climate risk reporting practices by UK insurance firms and pension schemes
}

\author{
[Institute and Faculty of Actuaries, Sessional Research Event, London, UK, 17 June 2019]
}

\begin{abstract}
This abstract relates to the following paper:

Klumpes, P., Acharyya, M., Kakar, G. \& Sturgess, E. (2019) Climate risk reporting practices by UK insurance companies and pension schemes. British Actuarial Journal, 24, e30. doi:10.1017/S1357321719000229.
\end{abstract}

The Chairman (Mr P. G. Meins, F.I.A.): Over the last few months, the government has agreed "We have a climate emergency." There seems to be an encouraging consensus amongst the political parties, which is adding to the momentum to take more steps to mitigate climate change. About 2 years ago, the Taskforce on Climate-Related Financial Disclosures issued its recommendations, and the Institute and Faculty of Actuaries (IFoA) published a risk alert requiring actuaries to consider what they should be doing about climate change. Tonight's meeting is an appropriate anniversary of those events. This paper is an important part of this journey to improve our practices and preparations for climate change.

Dr Paul Klumpes is an unusual participant in these halls in that he is not an actuary. He is an accountant by training. He holds academic positions at Birmingham University and Nottingham Business School. He was Professor for Accounting at Abu Dhabi University, Nottingham Business School and EDHEC Business School in France. He was Chair of Accounting at Imperial College London and Professor of Risk Accounting at Nottingham University Business School. He holds a law degree and various other degrees, and a PhD from the University of New South Wales. He is a Fellow of the Australian CPA Society and an Honorary Fellow of the Institute of Actuaries. His research interests cover the inter-relationship of public policy and voluntary reporting, regulation, financial management and control of financial services, particularly related to pensions and life assurance. He has been consulted by various financial, industrial and governmental organisations about risk management and reporting issues. He is chairman of the working party which produced tonight's paper. He is due to take up a Professor of Business position in Fujairah, UAE in August and then plans to go back to Australia to start playing golf.

Dr P. J. M. Klumpes, Hon. F.I.A. (introducing the paper): Actuaries are well placed to take leadership as a professional body. I want to contribute to this with the work that we have done as a working party. I have been involved in various working parties, but this one is of particular interest to lots of people, so it is great to see so many of you turn up.

I am going to give you an overview of what we have done. It is important to have the institutional background so you can see where the climate change comes from and then a little about the literature. We are a working party and not full-time academics at the moment, so the work we are doing is the tip of the iceberg on this really important area of work.

Although we have done a lot of work, we recognise that we are volunteers and we are not going to give a definitive view on the topic. This is a fast-moving subject, and developments in climate change are happening almost daily. We have done our best to keep up to date, but there are a few

\footnotetext{
(c) Institute and Faculty of Actuaries 2020. This is an Open Access article, distributed under the terms of the Creative Commons Attribution licence (http://creativecommons.org/licenses/by/4.0/), which permits unrestricted re-use, distribution, and reproduction in any medium, provided the original work is properly cited.
} 
caveats as we go through. I am aware that there are other working parties in the IFoA, which are looking at different aspects of the topic. My background is accountancy: the Taskforce for Climate Financial Disclosures (TCFD), which is related to the Financial Stability Board, is leading a lot of the generic reporting on the topic.

The other matter of interest to our working party is specifically from an actuarial perspective. What is its impact on insurance and on pension schemes? We are focusing on this particular sector, and many of you have knowledge of these sectors. We are not looking at environment social governance reporting, we are looking at climate risk reporting. That is a delineation. It is important for the pension schemes in the light of the recent parliamentary enquiries.

The TCFD have a specific set of recommendations. The main focus of our work is the Taskforce for Climate Change Disclosures, which came out in 2017, status report in 2018 and a new status report in 2019. They are looking at these specific four areas. Separate from that you have highlevel, global, voluntary disclosures which are mainly targeted to companies that are reporting to stakeholders through annual reports. In addition to that, in the UK's specific context, which is not mentioned by TCFD, the Prudential Regulatory Authority has been issuing guidance to insurers, in 2015 , in connection with the physical transition liability risks and then they updated that. On the pension scheme side, we have not had so much action from the regulator, but we have had quite a lot of action from the Parliamentary Environmental Audit Committee which has, in effect, forced transparency from pension scheme trustees.

In terms of where we have come from, I was working with a lot of people in the area of corporate governance, where we were looking at risks generally. Under the Revised Corporate Governance Code, there is a requirement which states that UK companies must comply with the generic obligation to say what is their financial viability moving forward as well as their risk management policy. What we have tried to do is move that on and look at the environmental risk space. I was here at an event, which I believe was run by the Research Environment Board, where the focus was on climate change. We migrated from environmental risk to climate risk, and that is an important clarification, but I will clarify this subtle difference between the two. Thank you to Marjory Gout and Emily Sturgess, and also Steven Soden and the research assistants as well as IFoA for funding for some of the work.

Our aim is to try to understand, at the industry level, what are these developments and are they impacting accountability conversations? Some of these conversations are happening formally through annual reports, sometimes they are happening outwith the annual report in separate reports. Then beyond that, there can be other conversations.

We are looking specifically in a UK context, so our work is an original contribution. We are only looking at the top insurers and the top pension schemes. Some of these schemes have been pre-defined for us by the Environmental Audit Committee Enquiry last year. In terms of the TCFD, it is not my role to give you the detail of that. I will refer you to their website in terms of the recommendations, but there are four areas: governance, strategy, risk management, and metrics and targets. For the financial industry, the risk management areas are important. If you are an oil and gas firm, climate change has a big impact in terms of performance metrics like carbon emissions. What is interesting to our working party is that pension schemes and insurers are not big hitters on carbon emissions, but, as the biggest investors and capital transformers in the market, they have a big impact surrogate-wise in terms of their policies, their assessments of their investments, and so forth.

It is important to point out that we have got these four areas, but risk management is a key issue for many of the audience here as well. Some of the obligations on climate change, particularly for insurance firms, are already embedded, either through Companies Act requirements generally, the Corporate Governance Code, Department of Food, Environment and Rural Affairs, and there are also Accounting Standards. These are quite specific and not really relevant to today. What is relevant are what we call the voluntary guidelines in connection with the topic. I will make reference to the Climate Disclosure Standards Board that issued some guidelines in 2015 and have just been 
updated this year to reflect climate risk. That is not in our paper, and that is more protocols of not just those four elements I referred to, but of a number of other elements. These are generic protocols, whereas the Climate-Related Financial Disclosure was quite specific as to 11 recommendations within these 4 areas. In looking at this issue, we have tried to think of a conceptual way of understanding the area. If you go into the environmental ethics literature, there is a formal communication, and that is the primary focus.

Who matters and what matters is a conversation that goes on between the reporting entity and its primary stakeholders, its shareholders, the creditors, credit rating agencies, regulators, etc. Why does it matter is going beyond the formal conversation that goes into annual reports and saying, are they engaged in the area? Are they not just reporting on it, to rubber stamp a requirement, or are they engaging, either through joining voluntary, UNEDP or Principles for Responsible Investment? Are they going beyond a formal conversation and actively engaging through that? We are looking at both the formal disclosures that meet the specific TCFD and going beyond that to look at more informal disclosures that are done outwith the annual report, and evidence that the organisation is engaging in the topic more generally.

The TCFD has undertaken extensive research on the topic, so in the year after it implemented the scheme, it then did an analysis in 2018 and they have just updated it to 2019. They do expect it could take up to 5 years for organisations to fully implement TCFD. They are looking globally and particularly at the top organisations, but as yet not looking at national trends, which is the difference between us. We are looking at UK bespoke rather than the international trends. There are conflicting results and it is part of the methodology, so we have tried to implement some of their methodology at a more granular level. There is a little bit of conflict between their results for insurers, on the one hand, seem positive on one level, but negative on another. They did not look at asset owners in 2018, they probably have done that in the latest one, but there are some issues there. There is a role for this research to contribute to that effort. In terms of explanations, one of the things we would like to understand is why do firms and pension schemes go to the hassle of complying with the requirements? Is it because they want legitimacy with the main organisations they are dealing with? Is it just managing impressions? Is it trying to reduce uncertainty by the key stakeholders about their exposure to the area? Is it just that they want to have a bit of engagement with the stakeholders more generally being conscious of these emerging, almost legal risks that are coming up with unhappy pensioners and other stakeholders concerned about the area?

We have just tried to think about that as a high-level point and not as yet explored further. However, there are now about a dozen papers in what is called Social Science Research Network where papers are coming out on climate change risk, but because the requirements have only just come out, there is a lack of research on the topic.

In terms of our specific research, we do two things. The main thing is to look at the TCFD requirements on climate risk, focusing on what goes in an annual report and are companies adopting as requested? Then, more generically, are they engaging, not necessarily in a specific area of report, but are they having narrative? Are they having a conversation in the report where they are engaging with other organisations, they are doing something on the reporting and they are implementing into their strategy, into their decision-making? We then try to go further looking at some of these theories to see what is the explanation, what is the reason they are engaging or not.

In terms of the insurance firms, we have selected the top 15 pension schemes. Some of the numbers in terms of total assets, from the latest consolidated balance sheets, may not include all policyholder assets. We had assumed they were UK firms but for Old Mutual, the only report available was an integrated report produced through the Johannesburg stock exchange, so I had to convert that from Rand and Brit Insurance to show their accounts in dollars, not pounds.(See Figure 1.)

On the pension schemes, there is a more homogenous list that I have taken straight from the Environmental Audit Committee Report.(See Figure 2.) 


\begin{tabular}{|l|l|r|l|l|}
\hline$\#$ & Name & $\begin{array}{r}\text { Total } \\
\text { Assets } \\
(£ b n)\end{array}$ & Speciality & Type \\
\hline 1 & Aviva & 430 & Combined & plc \\
\hline 2 & Prudential & 11 & Life & plc \\
\hline 3 & Hiscox & 7 & General & Private coy \\
\hline 4 & Admiral & 20 & General & plc \\
\hline 5 & RSA & 492 & Life & plc \\
\hline 6 & L\&G & 13 & Life & plc \\
\hline 7 & Standard Life Aberdeen & 47 & Life & plc (RSA) \\
\hline 8 & Old Mutual (ZAR) & 60 & Pensions & Private coy \\
\hline 9 & Phoenix & 18 & Combined & Society \\
\hline 10 & LV= & 6 & General & Private coy \\
\hline 11 & Brit Insurance (USD) & 19 & Combined & Society \\
\hline 12 & NFU Mutual & 118 & General & Society \\
\hline 13 & Lloyds & 15 & Health & Private coy \\
\hline 14 & BUPA & 9 & General & plc \\
\hline 15 & Direct Line & & & \\
\hline
\end{tabular}

Figure 1. Sample - insurance firms.

\begin{tabular}{|l|l|r|l|l|}
\hline$\#$ & Name & $\begin{array}{l}\text { Size } \\
\text { (Total } \\
\text { Assets £) }\end{array}$ & Sector & $\begin{array}{l}\text { Engaged GF } \\
\text { Comm Letter }\end{array}$ \\
\hline 1 & USS & 60 & University sector-wide & More \\
\hline $\mathbf{2}$ & BBC & 16 & Charities & More \\
\hline $\mathbf{3}$ & Strathclyde & 20 & Local Government & More \\
\hline 4 & HSBC & 27 & Banking & More \\
\hline $\mathbf{5}$ & Greater Manchester & 22 & Local Government & More \\
\hline $\mathbf{6}$ & BT & 49 & Telecommunications & More \\
\hline $\mathbf{7}$ & West Midlands & 14 & Local Government & More \\
\hline $\mathbf{8}$ & West Yorkshire & 14 & Local Government & More \\
\hline $\mathbf{9}$ & Electricity & 32 & Electricity sector wide & Less \\
\hline 10 & Railways & 25 & Railways sector wide & More \\
\hline 11 & British Airways & 16 & Airlines & Engaged \\
\hline $\mathbf{1 2}$ & BP & 24 & O\&G & Less \\
\hline 13 & Lloyds & 20 & Banking & Engaged \\
\hline 14 & HBOS & 15 & Banking CL & Engaged \\
\hline 15 & Mineworkers & 11 & Mining sector wide CL & Engaged \\
\hline
\end{tabular}

Figure 2. Sample - pension schemes.

The Parliamentary Committee made a judgement as to whether they thought the trustees, in responding to their request as to what they do about climate risk, were they more engaged, engaged or less engaged, with less engaged meaning they were not doing anything. Engaged means they equated climate risk to Environmental, Social and Governance (ESG). More engaged means they are doing something about climate change. We included only 15 pension schemes, as they voluntarily produce their accounts on the Web. 


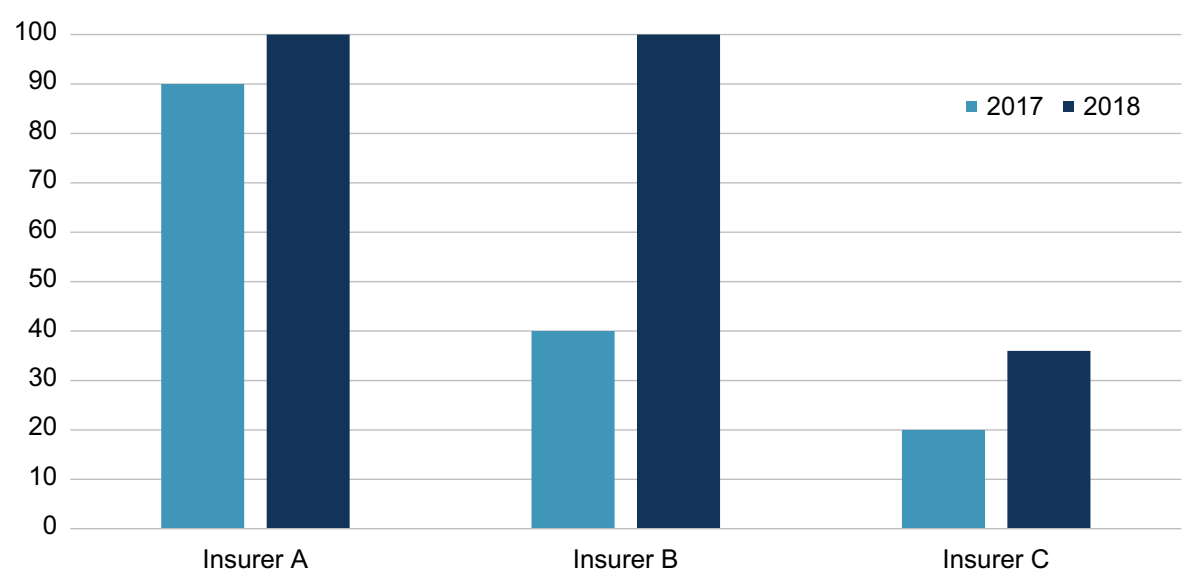

Figure 3. Degree of alignment with TCFD disclosures by UK insurance companies.

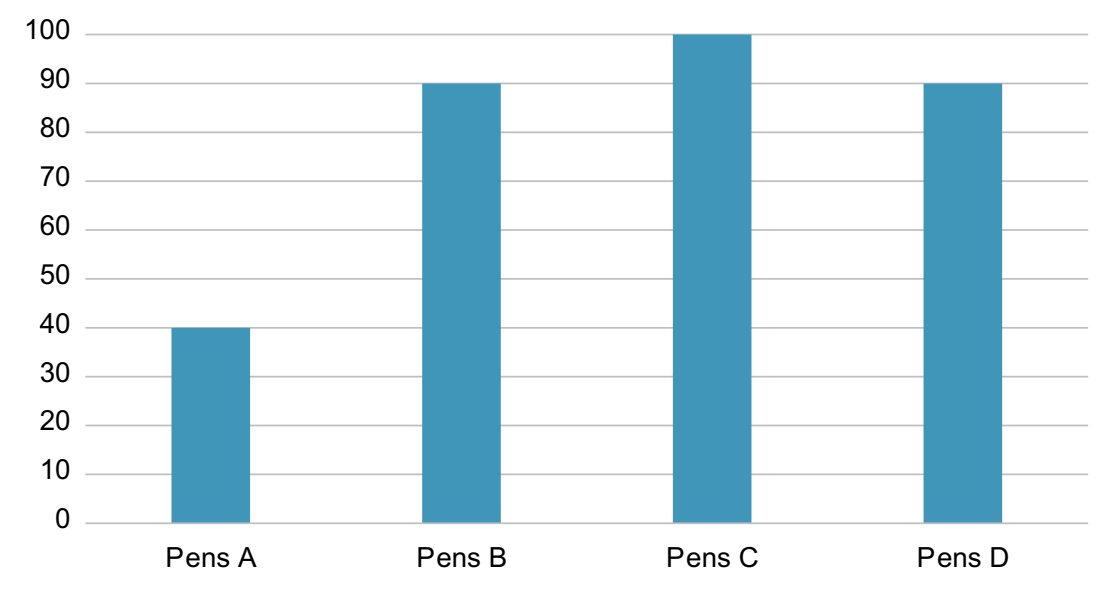

Figure 4. Degree of alignment with TCFD disclosures by UK pension schemes.

The problem with this research is that whereas with public companies, they are required by law to produce their annual report and that is then publicly produced. Pension schemes do not have that requirement at all. There are 25 pension schemes that were surveyed by the Environment Committee, but only 15 of those disclose their accounts on the Web which we could analyse.

In terms of research design, we had a look at the TCFD analysis, and then we looked at the more generic disclosures outwith the specific annual report obligation. We did then carried out some empirics, based on 15 schemes, and followed by a qualitative review where we identified the top disclosures.

In terms of the basic findings, the pension schemes have on average disclosed more. That is not a particularly good picture, because it is only a few schemes and a few insurers that seem to have more or less fully implemented the requirements.(See Figures 3 and 4.)

Looking at the individual insurers, for 2017 and 2018, we were able to get both years since TCFD. The latest reports, which mostly came out in March this year, showed a slight increment.

I am not allowed to disclose which insurers they are, but for those insurers that do seem to have implemented it, there are only 3 out of the 15 that have done a comprehensive job. You can see there is a gradual improvement. For the pension schemes, out of the 15 , only 4 seem to have really implemented it. 

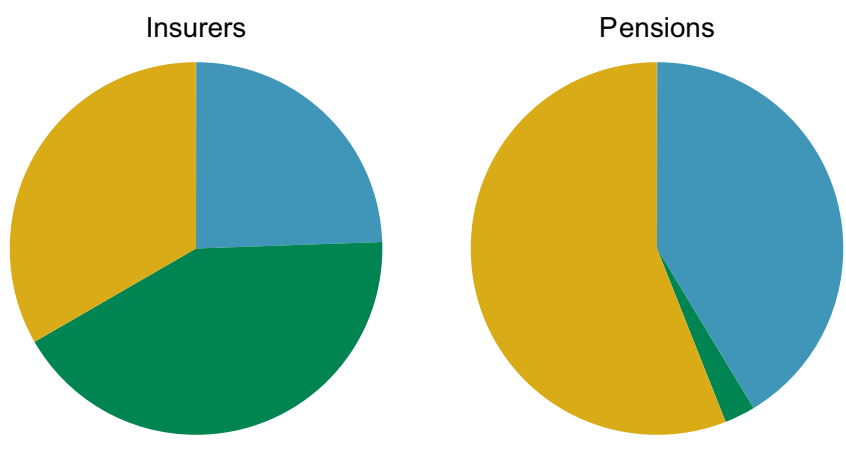

$\because$ Positive $\backsim$ Neutral $\backsim$ Negative

$\backsim$ Positive $\backsim$ Neutral $\backsim$ Negative

Figure 5. Engagement issues - insurers versus pension schemes.
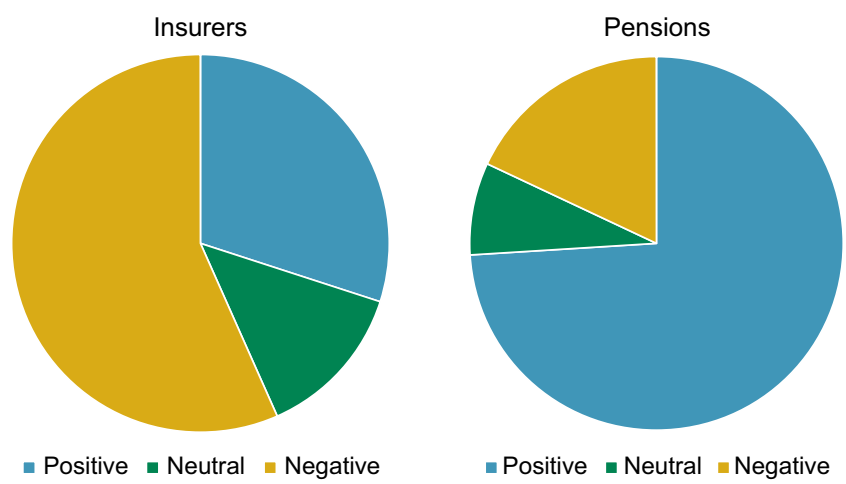

Figure 6. Action taken issues - insurers versus pension schemes.

I have only got one column because I do not yet have access to the 2018 accounts. You can see it is only those four that have made a big effort to more or less $100 \%$ implement the obligations or requests of TCFD.

This is now looking not necessarily at TCFD but looking at the engagement area. There are three areas we identified. One was engagement with outside organisations, for example, are they a member of ClimateWise? Are they a member of United Nations Environment Programme (UNEP)? All these clubs, where if you belong to them you can say, "I'm a member of them then somehow, it makes me look good." It turns out that in terms of the insurers and the pension schemes, there is quite a mix between those who do and do not engage, whereas, for the insurers, it is more ambiguous so we could not pick it out. For the reporting of policy issues, do they engage in terms of reporting the policy? The pension schemes were more engaged than the insurer.(See Figure 5.)

Finally, for action taken, do they implement the requirements in terms of their actual investment strategy? Do they challenge their investors and say, "Look, we are concerned about climate risk, what are you doing? Are you doing something about it in terms of reducing emissions or not? If you don't, I am going to divest from you." They were taking action in terms of implementing their requirements through their strategy.(See Figure 6.)

The problem with the insurers is if you have a more heterogeneous group, where you include general and life, and then public and private, whereas the pension schemes are more or less more homogenous. 
In terms of the generic position, we wanted to find out of the 15 who did voluntarily produce their annual report, as opposed to the 10 who did not, if there was a difference in terms of their generic position on climate risk as reported in their obligatory answer to the parliamentary enquiry. We do notice not a huge difference, but for the schemes who did voluntarily publish, there is generally more engagement than the ones who do not voluntarily produce their accounts on the Web.

Then we try to understand reasons why the pension scheme or insurer chooses whether or not to put their information in compliance with TCFD or more generally? Degree align is how many of the 11 they agree with. Engagement score is the extent to which they have engaged in the 16 topics defined in section 5.3.

Then, we chose a whole lot of other variables that might align. We thought liability risk in terms of information and symmetry. Obviously, size is about political visibility. We have also the investment risk side and then there are other governance issues like outside directors on the board or the types of business, for example, general or life. For pensions, are they single employer or multiemployer? Ownership structure, public sector, private sector for pensions and a publicly listed entity PLC versus private or a mutual for insurer are other topics, and then, eventually, type of entity.

In terms of degree of alignment, information asymmetry, if you look at Bloomberg, and all who developed TCFD, it was about informing the market about this information through the financials. In terms of generic disclosures, our suspicion was it is more like a political visibility, legitimacy story about showing to the members that they are engaging.

We find some variations with the life insurers tending to be more active in this space than the general insurers. The public sector schemes are more active in this space than private schemes. In terms of the alignment with disclosures, information asymmetry is a driver, but we have to be very tentative with our results, as we only have a very small sample. In terms of political visibility, it seems to be driving a lot of the action here. The larger you are, the more visible you are, the more complex that you are, the more expertise you will have to address these issues.

We have reviewed some examples of the kind of disclosures that we can see. In terms of insurer, what we picked out was there is a narrative where they are connecting the climate risk and then they are relating it to the regulatory authority requirements. They mention transitional risk and the link to physical risks, and that they are incorporating it into their policy. That seems to be more subtle, a little richer than insurers who do not address climate risk specifically in their narrative.

In terms of risk management, disclosures of a pension scheme, it is cookie cut. They are saying, so in this pension scheme they would site an actual requirement of the TCFD which was done in highlight and then they would answer each of those points. There are three areas within the risk management category and they would have a statement about what they were doing. Saying "this is a material risk, we are engaging with ESG, carbon foot-printing." They are having a narrative that is specifically addressing the requirement.

In terms of the more generic disclosures, we are now not looking at TCFD, but generally, for example, for a large insurer showing that they belong to the Asset Owners Disclosure Project and are a signatory to the Carbon Disclosure Project, and are ranked in the climate insurance index. They mention the UNEP, and they are implementing that. It is quite sophisticated that they are engaging with these external organisations and implementing TCFD and climate risk. For the pension scheme, it is a slightly different category. They are in clubs, which are slightly different clubs. Principles for Responsible Investment, Institutional Investment Group on Climate Change as well, and then they mention the Climate Action Group of Investors. Clearly, these pension schemes are demonstrating leadership in this area within their space.

It is really only a minority of entities that have specifically, explicitly addressed TCFD, not saying they are going to do something, but saying they have done something to address it now. Reputation risk is a big concern for the insurers, especially for those who are engaged at 
the coal face with the insurance actions. Pension schemes seem to be a more of a concern with the funding policy.

On the generic results, they do seem to be addressing the area on the investment strategy but we are talking about a few large listed insurance firms and mainly public sector, local government pension schemes (LGPSs) that are seen to be doing something about this, so lots of restrictions. We have been doing this work as these reports have been coming out in the last month, TCFD coming out last week, so that is a concern. Obviously, we want to keep this space open as the years go on.

Again we are working with a small sample size and are restricted to the available information, especially in the pension scheme space. That was created by the parliamentary enquiry which had to make trustees transparent and accountable to things they would not otherwise put in the public space.

We are looking only at hard information sources, so we have not gone into the more nebulous soft media, social media and other platforms that organisations are increasingly using to communicate to their stakeholders. Econometric tests were simplistic and we were trying to work out what some of the drivers were. Finally, the situation is evolving all the time. The UK government just made an announcement about neutrality on emissions and there have been international developments ongoing as we speak.

In terms of the specific, tip of the iceberg research, we would like to have a look at some other entities. "What is the public sector in the UK doing on this? What is the IFoA doing on this?" The assumption seems to be only the big guys produce a lot of pollution, but what about all the small to medium-sized enterprises and firms that are not big? In Australia, a whole election was fought on climate change. It was not fought on Brexit. It seems to be more of an issue in those countries than perhaps in the UK.

We have not drilled down to the four different areas within TCFD and this would be worth exploring. Some colleagues would like to look more in terms of the strategy, pricing and observing what are the connections to capital management. Climate risk reporting does need some further work. Much is focused on the asset side as an accountant, so a lot of consulting actuaries are pushing this. We have court cases coming up with people being unhappy about organisations role on climate risk, so what is the actuary's role in connection with the funding of insurers and pension schemes?

The Chairman: Thank you, Paul. It is very useful to have a viewpoint from an accountant, albeit almost an actuary as well, because climate disclosures impact both professions. We have to work together. For my part I am an actuary, formerly a member of the IFoA Resource and Environment Board, and am currently on the Research and CPD Committee of the Resource Environment Board.

Although the recommendations of the TCFD came out 2 years ago, we are in their early stages of the implementation, and it is a moving target with new surveys and reports coming out on a regular basis. It is great credit to Paul's working party that they produced this paper so we can see where we are now and focus on some of the issues. The TCFD recommendations are of crucial importance and they are not just about disclosure. They are about how you approach climate change, your strategy, your risk management, your key metrics and all the rest of it, which need to be considered before disclosing anything.

This disclosure is important for both company users and the users of accounts. Early adopters can provide helpful examples but there are differences here between pension funds and insurance companies. Insurance companies have to produce accounts which are publically disclosed. However, pension funds, although they are regulated and have to produce accounts, do not have to publically disclose them. It appears an anomaly but pension funds are private institutions set up by employers for their employees or private contracts between the owner of a personal pension policy and the insurance company. These are private arrangements but the justification for making them more public is that we have all contributed a huge amount in tax relief, as Philip 
Hammond keeps telling us, for pension funds. Also, there are massive funds involved which have a huge influence on the economy. There is a strong case for saying that pension funds ought to be disclosing more.

Pension fund actuaries, or anyone working in the pension fund industry, will bemoan that they have had enough of new requirements being gratuitously placed on the industry. But we are not talking about new documents: we are asking that the report and accounts already produced, including hopefully the TCFD disclosures, are made public on the Web. TCFD adoption is presently voluntary, but if pension funds make their documents public (I am only talking about the larger pension funds) that would add further scrutiny and impetus to the inclusion of climaterelated data.

Mr M. G. White, F.I.A.: My query is about the nature of the risks to insurers, as insurers rather than investors. From the point of view of an insurer, if you can keep reassessing your premiums and controlling your acceptances each year to cover the likely losses in that year, the problem of climate change, as far as it impacts your insurance result, is difficult but probably not life-threatening. You have to think carefully in relation to your investment strategy and also reputation risk, but there is another way in which things could conceivably hurt insurers. What might happen to the insurance industry if claims to their assureds emerge that relate to past years that you can no longer charge premiums for? For example, the energy companies could conceivably be in the frame. Is that something that you have discussed in the working party?

If you have insured energy companies over the years and something happens, some change in the law happens, they suffer, let's say, a class action when an island floods and somehow it comes back to an insurance claim, through to the insurance industry, that is an unmanageable aggregation. Is that something that you have thought about or that you have seen insurance companies discuss in their disclosures?

Dr Klumpes: I have noticed two things, in terms of the general insurers, they seem to give a statement that of the three risks, physical risks, transition and liability risks, they don't seem to think it is very important. The other thing I have seen, not just in terms of class action against energy firms, but US governments are now taking oil and gas firms to court for things like breaches of defences of flood walls, and using climate change to justify actions against NonGovernmental Organisation firms. I recently noticed in the financial times articles implying general insurers seem to be dismissing the liability risk as not being a major issue for them.

Dr L. M. Pryor, F.I.A.: I am Chair of the Resource and Environment Board of the IFoA and it may be helpful to say something about what the IFoA is doing on this front. Firstly, as the TCFD proposals have gone through consultation, the IFoA has responded to the consultations and been very supportive because we believe that disclosure and transparency are good things. The Resource and Environment Board has supported working parties that are preparing practical guides for actuaries in various fields about how climate risk might affect the work they are doing. So far, we have published practical guides for actuaries in pensions and defined contribution pensions, with supporting documents on financial assumptions, mortality and covenant assessment. Many of those contain useful information for people working in other fields as well, especially life insurance. Guides for life insurance actuaries, general insurance actuaries and investment actuaries should be out quite soon. We also have a general guide on an introduction to climate change for actuaries. As you are aware, there is a risk alert that was issued a couple of years ago saying that all actuaries should at least be aware of whether they are taking climate risk into account in the work they do and the advice they give to their clients.

Climate risk is a huge problem, and it is a significant financial risk. If you are not thinking about it on behalf of your clients, then you should be. There is a huge reputational risk here, both for you personally and for the profession as a whole. If things go horribly wrong, which they are quite likely to do, and actuaries have not been telling the people they are advising that this is a long-term financial risk, it is not going to be good. We were talking about liability risk and that actuaries possibly face liability risk themselves. Also, many actuaries come up to me and ask, 
"What can I do about climate change? What can I do to help?" Actuaries can help by talking about the financial risks of climate change to their clients. One of the best things anyone can do is just to talk about the problem because that will help more people become aware of what is going on. If you talk to your clients about this, you are doing a good thing.

Also, there are huge opportunities here in the TCFD and disclosures world. We have a lot of actuaries working in insurance, especially working on the Own Risk and Solvency Assessment process. A lot of them are getting involved in climate-related disclosures and that seems to be the part of insurers that is especially concerned with TCFD. There are huge opportunities here for actuaries, both in the insurance world and working with other professionals, to help not only insurers but other entities in their TCFD disclosures. We are also starting a joint working party with Institute of Environmental Management and Assessment (IEMA), the association of sustainability consultants, on a user's guide to TCFD. What can people reading the TCFD disclosures expect to get out of them and how can they use them? This will also help those people preparing the disclosures to think about what should go into them.

The Chairman: Just to elaborate on IEMA that Louise (Prior) mentioned, it is the Institute of Environmental Management and Assessment, so it is outside of our traditional sphere. It is quite an exciting development for actuaries, working with that organisation.

Mr M. J. Clark, F.I.A.: Paul referred to the letter which the House of Commons Environmental Audit Committee (EAC) wrote to 25 pension schemes, which I drafted. I also worked with ClientEarth, to follow up on that letter, who wrote to some of the pension schemes, collating their reply and then sending them five pages of what they should do next. I claim some credit for them not writing to all of them because with the "More Engaged," we should begin to applaud what they are doing, rather than criticise them. I also represent the IFoA on the Oxford Smith School Sustainable Finance Programme. The EAC letter also raises, for me, an interesting public policy issue. The The Pensions Regulator (TPR) could have done that, but Parliament went around the TPR and asked some questions directly.

A Shell Pension fund member in this country has complained about the lack of action by his trustees. That escalated to the trustees; he did not get satisfaction, so the complaint is now with the Pensions Ombudsman. We are not quite sure what is going to happen there. Such referrals are normally about how late contributions have been paid, or not paid. The Pensions Ombudsman and climate risk seem unusual bedfellows. There is a similar case in Australia where a member of one pension scheme has complained.

Moving onto the risk point, there is a public publication identifying the liabilities which have been referred to that actuaries currently bear. There is the ClientEarth Guide to Actuaries' Liability Risk, which I commend to you.

There is an interesting debate in The Actuary where one or two members of our profession seem unconvinced. I encourage you to convince any of our members that this is not a relevant risk to evolve their opinion. One of the things we miss is evaluation. One of the delightful things of Paul's paper is being able to produce data and evaluate. We do not have enough public interest money evaluating, like the Asset Owners Disclosure Project or the work of Dutch Association of Investors for Sustainable Development in the Netherlands. We need more evaluation.

I have written a piece on the Climate Change Committee, suggesting they establish a new subcommittee, the finance and investment subcommittee, because of the net-zero recommendations, which we have now just put into regulation. The finance sector is probably still missing a bit in terms of what could be done. To this point about climate coming out of the ESG morass, one ESG risk, which is clearly front and centre in asset owner risk, is climate. Most of the ESG issues are investment manager issues, but climate risk is out there.

Dr Klumpes: One of the things that I find quite strange is that people bandy around ESG, but ESG disclosures are often proprietary. It is not an obligatory requirement under any law to produce the ESG scores. A lot of consultancy firms have got control over that. I am very cautious about ESG as a concept because it is not totally transparent. Outwith the European 
Parliament making statements about legislation for ESG, it is a bit of a rubbery figure. Climate change disclosures are more direct disclosures that are looking at specific aspects of climate risk generally. ESG is a broad concept and the Parliamentary Committee did discriminate between pension schemes that failed to delineate climate risk accountability from broader ESG conversations.

The Chairman: Paul (Klumpes) mentioned in the paper and presentation that one of the possibilities is for actuaries to get involved in implementation of the TCFD recommendations. Certainly, that must be the case in relation to our traditional fields, like insurance and pension funds: climate change is all about looking to the future, at strategy, risk management and things like that.

I understand there was an interesting report from a recent meeting of the Pensions and Lifetime Savings Association that $50 \%$ of their audience had not heard of the TCFD. You could say $50 \%$ had. I suppose that is good news: it is the traditional problem of many of our pension clients being lay people. They are not experts in this field and so this is one of those issues where we have to explain why they need this service before we can provide it.

Dr Klumpes: I am talking about this as an accountant, but it is to do with the level of entity, the unit of analysis. TCFD seems to be cookie-cutting to firms which are listed, where there is a reporting entity that then has not just insurers, but maybe other entities. I suspect many of those in the audience might be working for a regulated entity, which is underneath or a subsidiary to what we might call the reporting entity, the consolidated entity.

In my research, I focused on UK insurers which were based in the UK. I did not look at American International Group nor AXA, because these are foreign entities where there are lots of climate reporting obligations in those countries for the reporting group. If those entities play a big role in insurance in this country but their regulated subsidiary is reporting up to Paris or Frankfurt and not to London, it will not be seen as at the same level because I am assuming, as an accountant again, there is a lot of action going on here within the organisation, at the head office where there is a communication going on with the sustainability director at that level.

I am concerned with the conversations here: if you are talking at a regulated entity concept, you are concerned about Prudential Regulation Authority (PRA), but our research is looking at the reporting entity. I was assuming the UK, number two, your job is to have a conversation with communication directors, as well as just other actuaries.

The Chairman: In relation to pension funds, there are a number of different professionals involved, including the Scheme actuary advising the trustees, a different actuary advising the company, and a different actuary or investment consultant advising on investment policy and strategy. In addition, there is the Scheme auditor and appointed legal advisers. Any one of those parties may feel he has the authority and responsibility to engage his client with the disclosure topic. It is a relatively new area.

Dr Klumpes: As a transparency issue, I was almost inclined in the working party to ignore the pension scheme. I would just go to the sponsoring organisation, where they have got to report the pension liabilities under the Generally Accepted Accounting Principles (GAAP). The actuarial assumptions underlying pension costs, where you will see all the liabilities being disclosed through the covenant, may well be different sets of assumptions the trustee is depending on in terms of the advice given by the pension fund scheme actuary. They can use different discount rates and they are not required under the Statement of Recommended Practice or under FRS 102 to have to, what we call in accounting, recognise any liability. It is just the assets.

The Chairman: With your accounting experience and international perspective, how would you expect to see things developing with regard to TCFD?

Dr Klumpes: It is about the Americans and the capitalist perspective, which looks at TCFD focusing on asset owners. On the other hand, if you go into Europe and other countries where the model in the pensions is less laissez-faire and it is more an explicit contract in terms of having liability obligations, you will still have a greater emphasis in countries like Germany, for example, 
where there are risk reporting obligations. A lot of these obligations are unfunded and so the conversation on climate risk will then evolve more on the liability side than the asset side.

In Australia, climate risk is in the public space. In the governance perspective, public, there is a clearer governance link to parliament, the ombudsman is more powerful. In some countries, there are even ombudsmen for future generations. So there is a much clearer link for those kinds of arguments to take place.

The Chairman: Historically, you could say that imposing further requirements on external bodies like pension funds has been a relatively easy and attractive option for governments to do. One might well see them doing that in the future in relation to the TCFD recommendations because many other things concerning climate change are more difficult.

Mr Clark: Considering this another way, I am hearing this conversation as regulators and policymakers making us do something we do not want to do. It is more work. I would argue it is both the right thing to do and a good thing to do. I am a non-exec on the board of one of the new LGPS pooling companies. Many of you will be familiar with pension pooling. My board are committed to this being a risk to the beneficiaries of our clients and if regulation ever caught up with us, we would be slightly disappointed. We are doing this because it is the right thing and good thing to do. The California insurance commissioner, because there is a regulation which means they can view insurers' investment portfolios listed on the insurer's website, the California commissioner, Dave Jones, did an assessment of 612 insurance companies writing business in California.

In Switzerland, the pensions and insurance regulator did a similar thing. They did not have the power to ask for the information, so via a third-party firm called the $2^{0}$ Investing Initiative they collected the information from the insurance companies, aggregated it and gave it to the regulator who then said, "That is rather bad, we are heading to $5^{0}$." How many people have engaged with the Intergovernmental Panel on Climate Change report from the last quarter of last year which talks about $1.5^{0}$ ?

This is a climate catastrophe heading our way. As to regulation, to your non-UK point, there is the Network for Greening the Financial System. The regulators are joining up, so there are global conversations amongst regulators.

I cannot speak for the PRA, but my understanding is that when the regulation is put in place, not only boards have to be aware but also the Senior Management Function will have climate risk in their responsibilities, so that when things go wrong, these will be the people to go to. There is a missing link, which are the investment consultants, for example, 2 NGOs had to get 12 investment consultants to sign up a year ago to the following statement, and I paraphrase "We will take the Pensions Regulator's guidance on climate change risks to our clients."

The Chairman: It was announced the other day that global greenhouse gas emissions in 2018 were $2 \%$ higher than the year before. They have been basically flat lining in recent years due to reduction in the use of coal, but there is no sign of them trending down, which is what they need to do to meet the requirements of the UN Climate Paris Agreement.

I was involved with a paper on decarbonisation through the International Actuarial Association: why are we decarbonising, looking at the targets, and the possible implications for actuaries. Apart from the need to adapt to climate change, decarbonisation - attempting to mitigate climate change - is the big issue for pension funds and insurers because it will have a major effect on their investment strategies. It is one thing which they need to take account of as of now. Coming back to disclosure, we know that it is inching forwards with regard to pension funds. From October 2019, defined contribution schemes have to disclose their statement of investment principles and how they are dealing with climate change. From October 2020, defined benefit will also have to do that.

This is more piecemeal disclosure and it does not address the need to recognise climate risks in accounts, which TCFD does. I recognise I am not quite as balanced in my comments as Chairs normally are! 
Dr Klumpes: As an accountant, the thing that hits me is the TCFDs saying, "What about the financial impact of climate change on the accounts?" The accounts, the balance sheet, income statement, well, the funding position, it is in fair value, it is a number and the assumption behind accounting is going concern. One of the things I have been doing for my research is looking at the impact for credit rating and how covenants are rated by credit rating agencies. They are not looking at balance sheets and income statements, they are looking at cash flow.

If you want to have a conversation about the financial impact of climate change in the UK context, take into account the concern of the Financial Reporting Council about financial viability. It is cash flow, not balance sheet that is going to be hit. The whole concept of accounting is based on wealth being created through consumption. Is that the right model to understand the financial impact on climate change when it is about the consumption of an existing resource that will not be available in the future? It is the scarce resource, not resource consumption.

The existing accounting model, as implemented for some 500 years, may not be the right model to understand the impact of climate change on financials. One of the challenges of TCFD is "Yes, you are saying something about climate change, but what is its impact on your financials?" But which financials and what is the best way of modelling that? Actuaries have got a good grasp of Discounted Cash Flow and cash flow. It does seem to me that focusing on earnings and balance sheets is not the right way to have a conversation about climate change.

The Chairman: I know one firm of actuaries is, or were, marketing a service to value reserves for oil companies and do long-term evaluations in relation to the oil industry. This is an interesting departure for actuaries. One of the issues is why do we need this? Why aren't the accounts already giving us a true and fair view? The governor of the Bank of England has said recently that if we are going to combat or mitigate climate change, most of the existing reserves of oil will have to stay in the ground. In other words, they won't be worth very much, but in the balance sheets of major oil companies, they are showing massive reserves. There seems to be a contradiction there.

Dr Klumpes: We have got to be careful. In the US context, the definition of proven reserves is different from the definition that is acceptable under International Financial Reporting Standards (IFRS). There is a subtle point about the discount rate that one can use to discount these reserves. When the Canadians decided to go from Canadian GAAP to IFRS, all the oil and gas firms in Canada had to use a much tougher discount rate that was required under IFRS. These are quite subtle impacts: part of the problem is that the oil and gas industry in the United States do not want to have a conversation about climate change. They are not interested. I have looked at disclosures on oil and gas by Total and by European firms. They will have conversations in their reports about climate change, whereas the Americans do not want to know about it.

Mr Clark: Let me offer a project that I almost guarantee you an NGO will do in the next 5 years. An NGO will contact a range of oil companies and they will say, "I see what you say in your balance sheet of the value of the reserves. Now, we have some sensible assumptions about the future price of carbon, please tell us what that number is using these assumptions." So, we begin to look at the future bit of the balance sheet based on an assumed value of oil, which I would argue is highly likely to be overpriced or at least the assumption of the value of those reserves is misguided.

Dr Klumpes: It is not just the NGOs. Credit rating agencies are getting worried about some of these issues: they were consulted on the TCFD recommendations. In terms of the separate research I have done looking at US firms, the credit rating agencies are tracking the cash flow. When it comes to a marginal decision about speculative grade versus investment grade, a lot of the oil and gas firms try to manipulate their accounts in order to manage that credit rating threshold. Separate research is starting to come out that the credit rating agencies are looking at the fundamentals here and it is not just the earnings.

The Chairman: That is encouraging, particularly after the problems the credit rating agencies had in the last crisis. 
We have had a wide-ranging discussion. The reason that there are so many people here is that we are all concerned about climate change. It is something we are all going to be grappling with over the coming decades. We are at a relatively early stage, but need to act now.

I and we would like to express our thanks to Paul Klumpes and the working party in the usual way.

Cite this article: Climate risk reporting practices by UK insurance firms and pension schemes. British Actuarial Journal. https://doi.org/10.1017/S1357321720000057 